\title{
Kinetics and Mechanism of the Conversion of Cyclobutenones to Vinylketens
}

\author{
By Herbert Mayr and Rolf Huisgen* \\ (Institut für Organische Chemie der Universität, 8 München 2, Karlstr. 23, Germany)
}

\begin{abstract}
Summary The structure-rate relationships for the electrocyclic ring opening of phenylated and alkylated cyclobutenones to vinylketens, though not fully understood, resemble those which are observed in cyclobutene ring openings.
\end{abstract}

Optically active 2,4-dichloro-3-phenylcyclobutenone racemises through a small equilibrium concentration of a vinylketen. By comparison of the racemisation and ringopening rates, Jenny and Roberts ${ }^{1}$ observed that the recyclization can be prohibited by interception of the vinylketen with ethanol. The racemisation rate constants showed only a small solvent influence. A convenient synthesis of phenylated and alkylated ${ }^{2}$ cyclobutenones has encouraged us to investigate the structure-rate relationship of the electrocyclic ring opening to vinylketens. Furthermore, analysis of the products which are formed from 2,4-dimethyl-4-phenylcyclobutenone in cyclohexane ${ }^{3}$ and

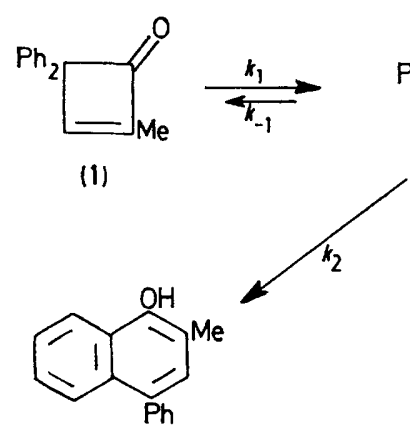

(3)

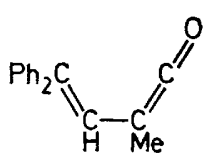

(2)

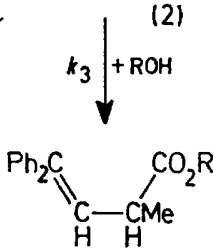

(4) in methanol ${ }^{4}$ indicated that the ring opening reaction is virtually irreversible, i.e., the vinylketen predominates in the equilibrium.

\section{TABLE 1}

Rate constants for the conversion of 2-methyl-4,4-diphenylcyclobutenone (1) into $(3)$ or $(4)$ in various solvents at $55^{\circ} \mathrm{C}$.

\begin{tabular}{|c|c|c|c|c|}
\hline \multicolumn{3}{|c|}{ Solvent } & $E_{\mathbf{T}}$ & $\begin{array}{c}10^{4} k_{\mathrm{ex}} \\
/ \mathrm{s}^{-1}\end{array}$ \\
\hline Cyclohexane & . & . & $31 \cdot 2$ & $5 \cdot 36$ \\
\hline Benzene & & & $34 \cdot 6$ & $4 \cdot 14$ \\
\hline Ethyl acetat & $\ldots$ & $\ldots$ & $38 \cdot 1$ & 2.53 \\
\hline$N N$-Dimeth & ylformamide & .. & $43 \cdot 8$ & $1 \cdot 75$ \\
\hline Acetic acid & . $\quad \ldots$ & . & $51 \cdot 1$ & 1.83 \\
\hline Ethanol & $\ldots$ & . & $51 \cdot 9$ & $2 \cdot 01$ \\
\hline Methanol & $\ldots$ & $\ldots$ & $55 \cdot 5$ & 1.78 \\
\hline
\end{tabular}

The first-order rate constants for the conversion of (1) to (3) or (4) in various solvents (Table 1) were measured by u.v. spectrophotometry. The small inverse dependence of $k_{\exp }$ on solvent polarity, for which $E_{\mathbf{T}}$ is an empirical parameter, $^{5}$ is in agreement with a concerted electrocyclic ring cleavage $(\mathbf{1}) \rightarrow(2)$. The dipole moments of ketens are somewhat smaller than those of analogously substituted ketones $^{6}$ and hence the same relationship may be valid for cyclobutenones and vinylketenes. The underlying assumption $k_{\exp }=k_{1}$, i.e., the measured rate equals the ringopening constant, is supported by the near identity of $k_{\mathrm{exp}}$ in two solvents, ethanol and acetic acid. While in the latter case the naphthol $(3)$ is the only product, $60 \%(4, \mathrm{R}=\mathrm{Et})$ and $40 \%(3)$ are formed in ethanol. Nevertheless, the partition coefficient

$$
k_{\exp }=k_{1} \frac{k_{2}+k_{3}}{k_{-1}+k_{2}+k_{3}}
$$

(where $k_{3}$ is the pseudo first-order constant in alcohol as solvent) appears to be close to unity, i.e., $k_{-1}<<k_{2}, k_{3}$.

By similar kinetic methods the ring-opening rates of additional cyclobutenones were measured (Table 2); they range over four powers of ten and are not easily understood. Substitution of $2-\mathrm{H}$ by a methyl group reduces $k_{\exp }$ by a

TABLE 2

Rate constants for the ring opening of various cyclobutenones in methanol at $80^{\circ} \mathrm{C}$.

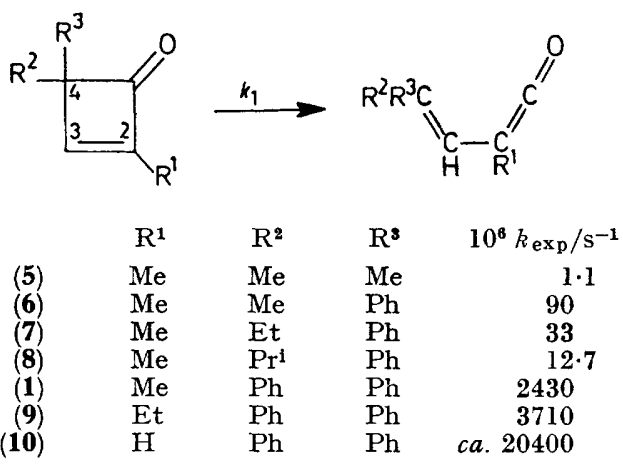

factor of 8. The two 4-substituents of cyclobutenone attain conjugation in the vinylketen. The first replacement of 4-methyl by 4-phenyl increases $k_{\mathrm{exp}} 82$ fold and the second 27 fold, corresponding to $\Delta \Delta G^{\ddagger}=3 \cdot 1$ and $2 \cdot 3 \mathrm{kcal} \mathrm{mol}^{-1}$. Phenyl and methyl groups stabilize a double bond by $\mathbf{4 . 9}$ and $3.2 \mathrm{kcal} \mathrm{mol}^{-1}$, respectively. ${ }^{7}$ Only a fraction of this difference, $1.7 \mathrm{kcal} \mathrm{mol}^{-1}$, should become effective in the transition state of the ring opening. Thus the conclusion appears unavoidable that the transition states profit more from phenyl conjugation than the products.

The experimental $(Z) /(E)$ product ratios ${ }^{4,8}$ allow the breakdown of $k_{\exp }$ for $(\mathbf{6})-(\mathbf{8})$ into the partial rate factors shown in Table 3 . The decrease in $k_{1}$ and $k^{\prime}{ }_{1}$ in going from $\mathrm{Me}$ to $\operatorname{Pr}^{1}$ suggests that the transition states suffer more from van der Waals repulsions than the reactants. The rapid decrease in the formation of the $(E)$-vinylketen relative to the $(Z)$-isomer would accord with a steric hindrance of resonance in the vinylketens.

Since the cyclobutene to butadiene conversion shows similar substituent effects, the mechanistic analogy of the two electrocyclic reactions is emphasized and justifies the assumption $k_{\exp }=k_{1}$. Rate constants at $80^{\circ} \mathrm{C}$ were 


\section{TABLE 3}

Partial rate constants for the ring opening of 4-alkyl-2-methyl4-phenylcyclobutenones to the $(Z)$ - and $(E)$-vinylketen in methanol at $80^{\circ} \mathrm{C}$<smiles>[R]/C(=C/C(C)=O)C(C)=O</smiles>

(Z)

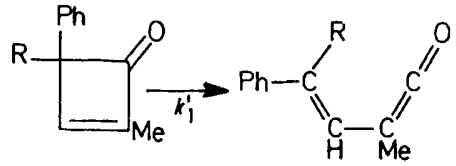

(E)

$\begin{array}{lcc}\mathrm{R} & 10^{6} k_{1} / \mathrm{s}^{-1} & 10^{6}{k^{\prime}}_{1} / \mathrm{s}^{-1} \\ \mathrm{Me} & 22 & 68 \\ \mathrm{Et} & 11 & 22 \\ \operatorname{Pr}^{1} & 9 & 3\end{array}$

calculated from activation energies previously reported in the literature.

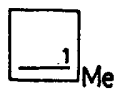

0.012

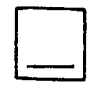

0.093

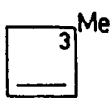

$1 \cdot 0$

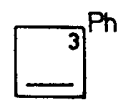

200
The ring opening rate of cyclobutene ${ }^{9}$ is decreased 8 fold by 1-methyl substitution. ${ }^{10}$ The replacement of $3-\mathrm{H}$ by methyl ${ }^{10}$ and phenyl ${ }^{11}$ increases $k_{1} 10$ and 2000 fold, respectively; consequently, each phenyl substituent in the 3 and 4-position reduces the $E_{\mathrm{A}}$ by $c a .5 \mathrm{kcal} \mathrm{mol}{ }^{-1} .11$

The approximate additivity of substituent effects allow one to estimate $k_{1}=1.4 \times 10^{-6} \mathrm{~s}^{-1}$ for $1,3,3$-trimethylcyclobutene. This value is similar to the ring-opening constant of 2,4,4-trimethylcyclobutenone (5) in Table 2. Surprisingly, substituents seem to influence the ring opening rate of cyclobutene to a greater extent than the replacement of the 3-methylene group by a carbonyl group.

(Received, 20th October 1975; Com. 1186.)

1 E. F. Jenny and J. D. Roberts, J. Amer. Chem. Soc., 1956, 78, 2005.

${ }^{2}$ H. Mayr and R. Huisgen, Angew. Chem. Internat. Edn., 1975, 14, 499.

${ }^{3} \mathrm{H}$. Mayr, Angew. Chem. Internat. Edn., 1975, 14, 500.

$4 \mathrm{R}$. Huisgen and $\mathrm{H}$. Mayr, preceding communication.

5 K. Dimroth, C. Reichardt, T. Siepmann, and F. Bohlmann, Annalen, 1963, 661, 1; C. Reichardt, 'Lösungsmitteleffekte in der organischen Chemie,' 2nd edn., Verlag Chemie, Weinheim.

${ }_{6}^{6}$ C. L. Angyal, G. A. Barclay, A. A. Hukins, and R. J. W. LeFèvre, J. Chem. Soc., 1951, 2583.

7 J. Hine and N. W. Flachskam, J. Amer. Chem. Soc., 1973, 95, 1179.

${ }^{8} \mathrm{H}$. Mayr, Ph.D. Thesis, University of Munich, 1974.

${ }^{9}$ W. Cooper and W. D. Walters, J. Amer. Chem. Soc., 1958, 80, 4220.

${ }^{10}$ H. M. Frey, Trans. Faraday Soc., 1962, 58, 957; 1964, 60, 83.

${ }^{11} \mathrm{M}$. Pomerantz and D. H. Hartmann, Tetrahedron Letters, 1968, 991. 